\title{
PROBLEMATIZAÇÕES CONSTITUINTES DA JUVENTUDE ESTUDANTIL CONTEMPORÂNEA ${ }^{1}$
}

\author{
Dorgival Gonçalves Fernandes ${ }^{2}$
}

\begin{abstract}
RESUMO:
Neste artigo, a partir de mapeamento sobre a produção acadêmica acerca da juventude estudantil brasileira na contemporaneidade publicada em periódicos nacionais, buscamos compreender o processo de constituição da juventude estudantil por meio do discurso acadêmico. Em tal discurso, majoritariamente referente a estudantes de escolas públicas, analisamos os temas e as problematizações enunciados sobre a juventude estudantil, entendendo, a partir do pensamento de Michel Foucault, que a prática discursiva constitui o objeto sobre o qual fala. Os temas enunciados e problematizados pelo discurso acadêmico na constituição da juventude estudantil como condição e lugar de sujeito, são: Juventude, escola e escolarização; Juventude, educação e mídias; Juventude, educação e trabalho; Juventude e educação não-formal; Juventude, educação e violência; Educação e jovens em conflito com a lei; Juventude, educação e sexualidade e Educação e protagonismo juvenil. Tais temas, no processo de constituição referido são postos no discurso acadêmico em situação de complementaridade e interdependência. Segundo os discursos analisados, a juventude estudantil é constituída a partir de um lugar de sujeito inferiorizado na escola, e nesta, luta pela conquista de respeito e autonomia enquanto sujeito discente, pelo reconhecimento das suas necessidades e demandas específicas no que se refere à aprendizagem escolar, bem como pela valorização da cultura juvenil e da sua condição de jovem nessa instituição. Para a maioria dos jovens estudantes, a escola se configura como lugar de tensão e conflitos. Assim, a constituição da juventude estudantil é pautada por tensão e conflitos, principalmente quanto à disciplinarização imposta pela escola e a autonomia desejada pelos jovens estudantes.
\end{abstract}

Palavras-chave: Jovens estudantes. Discurso acadêmico. Escola. Processos de constituição. Michel Foucault.

\section{CONSTITUENTS PROBLEMATIZATIONS OF CONTEMPORARY STUDENT YOUTH}

\begin{abstract}
:
In this article, from mapping of the academic production about the Brazilian student youth in contemporary published in national journals, we aim to understand the formation process of student youth through academic discourse. In this discourse, mostly related to public school students, we analyze the listed issues and questioning about the student youth, understanding, from the thinking of Michel Foucault, that the discursive practice constitutes the object of this own speech. The themes enunciated and problematized by the academic discourse in the constitution of the student youth as condition and place of subject, are: Youth, school and schooling; Youth, education and media; Youth, education and work; Youth and non-formal education; Youth, education and violence; Education and youth in conflict with the law; Youth, education and sexuality and Education and youth protagonism. Such themes, in the process of constitution referred to are placed in the academic discourse in a situation of complementarity and interdependence. According to the analyzed speeches, the student youth is constituted since a place of lessen subject at school, and in there, struggle for respect and autonomy as fellow students, for the recognition of their specific needs and demands in regard to school learning, as well as to the appreciation of youth culture and their young condition in that institution. For most young students, the school is set up

\footnotetext{
${ }^{1}$ Este artigo é parte do nosso trabalho de pós-doutorado desenvolvido na Faculdade de Educação da Universidade de São Paulo.

${ }^{2}$ Possui Graduação em Pedagogia pela Universidade Federal da Paraíba (1988), Mestrado em Educação pela Universidade Federal da Paraíba (1997), Doutorado em Educação pela Universidade Federal de São Carlos (2003) e Pós-Doutorado em Educação pela Universidade de São Paulo (2015). Atualmente é professor associado III da Universidade Federal de Campina Grande, campus de Cajazeiras. Email: dorgefernandes@yahoo.com.br.
} 
as a place of tension and conflict. Therefore, the formation of student youth is marked by tension and conflicts, especially regarding the disciplining imposed by the school and the desired autonomy among students.

Keywords: Young students. Academic discourse. School. Formation processes. Michel Foucault.

\section{Introdução}

Neste artigo buscamos empreender um mapeamento da produção acadêmica brasileira acerca da juventude estudantil contemporânea presente em periódicos nacionais do campo educacional publicados entre os anos de 2004 a 2013, visando compreender como a juventude estudantil tem sido apreendida, problematizada e, afinal, constituída nos discursos sobre ela. Propomo-nos, desse modo, pensar o conjunto de questões que sustentam tal produção, perspectivando as dinâmicas de pensamento que têm nutrido o campo de estudos sobre a juventude no quadrante educacional.

Assim, objetivamos trazer uma contribuição para o debate sobre a relação juventude e educação ao mapear e dar visibilidade às temáticas e problematizações que têm coberto a diversidade de estudos sobre a juventude. A opção por trabalharmos com artigos publicados em periódicos deveu-se ao entendimento de que, segundo Packer (2011), o periódico, além de favorecer acessibilidade e visibilidade dos conhecimentos produzidos pela comunidade acadêmica, contribui para o avanço do conhecimento nas áreas temáticas específicas, integrando a memória e os fluxos de informação científica. Teoricamente nos pautamos no pensamento foucaultiano, centrando-nos em noções, tais como: sujeito, discurso, governamentalidade e arquivo.

\section{Procedimentos da pesquisa e caracterização do arquivo}

Para selecionar os periódicos, tomamos como critério a sua inserção/circulação no meio acadêmico e sua classificação aferida pelo sistema Qualis-Periódicos da CAPES. Nesse caso, optamos pelos seguintes 20 periódicos: Cadernos CEDES, Cadernos de Educação, Cadernos de Pesquisa, Currículo sem Fronteiras, Educação \& Realidade, Educação \& Sociedade, Educação PUCRS, Educação e Pesquisa, Educação em Questão, Educação em Revista, Educação Temática Digital, Educar em Revista, Perspectiva, Práxis Educativa, Pro-Posições, Revista Brasileira de Educação, Revista Brasileira de Estudos Pedagógicos, Revista da FAEEBA, Revista de Educação Pública e Revista Diálogo Educacional.

Para constituir o arquivo com os artigos a serem analisados, detivemo-nos no conjunto dos resumos publicados nesses periódicos, computando um total de 6.824

\begin{tabular}{|l|l|l|l|l|}
\hline Govista Dialectus & Ano 4 & n. 11 & Agosto - Dezembro 2017 & p. 29-49 \\
\hline
\end{tabular}


textos. Para a identificação dos artigos referentes à juventude estudantil, utilizamos os seguintes descritores: adolescência, adolescente, juventude, jovem(ns), estudante(s), aluno (a, os, as), juvenil(is), Ensino Médio, universitário (a, os, as). Concluída a triagem dos resumos, chegamos ao patamar de 171 artigos sobre a juventude estudantil.

\section{Temas e problematizações enunciados}

Na organização dos temas e problematizações sobre a juventude estudantil nos periódicos selecionados, entendemos os temas como elementos constituintes de um mapa rizomático, à maneira deleuziana, propondo-nos a agrupá-los como pontos móveis de uma rede que visa à multiplicidade, formando "um conjunto de anéis quebrados que podem penetrar uns nos outros" (DELEUZE, 1992, p. 37). Quanto às problematizações engendradas nos temas, consideramo-las, ao modo de Foucault (2004, p.242), como uma prática discursiva que constitui objeto para o pensamento.

Levando em conta a multiplicidade das problematizações evidenciadas nos artigos, agrupamo-las de acordo com os seguintes temas: 1) juventude, escola e escolarização; 2) juventude, educação e mídias; 3) juventude, educação e trabalho; 4) juventude e educação não-formal; 5) juventude, educação e violência; 6) educação e jovens em conflito com a lei; 7) juventude, educação e sexualidade; e 8) educação e protagonismo juvenil. Vejamos, a seguir, um a um deles.

\section{Juventude, escola e escolarização}

Esse tema assumiu preponderância nos estudos sobre a juventude, imbricando-se com os demais temas assinalados. Assim, podemos evidenciar que, na atual configuração social marcada por crises provindas de mutações sociais, a escola continua sendo uma instituição exemplar, "destinada à produção de subjetividades, à produção de sujeitos, à construção e veiculação de identidades, à definição de lugares de sujeito", conforme assinalou Albuquerque Junior (2010, p. 55).

Nesse sentido, como instituição disciplinar calcada em um projeto moralizante, a escola estaria investindo sobre o jovem estudante um lugar de sujeito forjado na menoridade e subalternidade em relação aos sujeitos escolares adultos. Nessa perspectiva, na maioria dos estudos, a escola desponta como lugar de tensão e conflito.

Os artigos evidenciaram que os jovens estudantes estariam a ansiar por participação e respeito na escola, defrontando-se, porém, com gestões pouco democráticas que não os reconheciam como sujeitos de direitos, percebendo-os apenas

\begin{tabular}{|c|c|c|c|c|}
\hline Qevista Dialectus & Ano 4 & n. 11 & Agosto - Dezembro 2017 & p. $29-49$ \\
\hline
\end{tabular}




\section{PROBLEMATIZACÕES CONSTITUINTES DA JUVENTUDE ESTUDANTIL... Dorgival Gonçalves Fernandes}

na condição de aluno, tendo por referência o aluno infantil. Os jovens valorizavam os conhecimentos escolares, considerando-os necessários para a conquista de um suposto futuro melhor, reputando a escola como instituição fundamental na promoção de conhecimentos para o seu desenvolvimento, assim, reclamavam por uma escola que ofertasse educação de qualidade e considerasse os seus anseios, dificuldades e culturas.

Porém, diante de uma escola que não satisfaz tais demandas, os jovens sentiamse desmotivados mediante a rotina escolar e às incertezas do futuro, responsabilizandose por sua desmotivação, sucesso ou fracasso escolar, e, às vezes, penalizando-se. Parte dos alunos, assim, procurava investir nas disciplinas ministradas por professores de que gostavam, diminuindo o investimento na sua aprendizagem escolar e carregando consigo certo sofrimento, como afirmado por Reis (2012).

A partir de estudo elaborado numa escola pública, Sposito e Galvão (2004) apontaram que os jovens estudantes tinham uma percepção de si oposta à percepção alimentada pelos docentes, o que dificultava a socialização entre docentes e discentes. Os alunos tomavam como referência de bom professor o docente que desenvolvia uma relação de companheirismo com os estudantes, envolvia-os no processo de ensinoaprendizagem, explicava bem os conteúdos e era compromissado com o seu trabalho.

Todavia, segundos as autoras, não muito frequentemente os alunos pesquisados deparavam com professores que assumiam esse perfil, classificando os demais, muitas vezes, como autoritários e desrespeitosos na prática pedagógica, e atribuindo a eles grande parte das humilhações, injustiças e violência que vivenciavam na escola. Sposito e Galvão (2004, p. 371) afirmaram que "os estudantes apontavam as humilhações como a maior experiência de violência sofrida [e que] na relação com o professor, a falta de respeito é prática claramente distinta de humilhação".

Nos artigos que refletiram sobre escolas particulares, não encontramos referências a humilhações e violência, mas registramos reclamações discentes acerca do autoritarismo exercido por docentes e gestores, considerando injusto, abusivo e desprovido de sentido o uso da autoridade como mera demonstração de poder. Os estudantes, como estratégias de resistência a tal situação, assumiam para si uma economia visando a evitar um esforço escolar "excessivo" e punições, estabelecendo comportamento e atitudes circunstanciais frente à sua escolarização, de acordo com o estilo de trabalho e a personalidade do professor, bem como com as regras e normas escolares, nem sempre consideradas claras, coerentes e justas.

\begin{tabular}{|l|l|l|l|l|}
\hline Govista Dialectus & Ano 4 & n. 11 & Agosto - Dezembro 2017 & p. 29-49 \\
\hline
\end{tabular}


Nessa relação tensa e conflituosa com a escola, os jovens alunos indicaram experimentar na vida escolar sentimentos de incompreensão e solidão. Esses reclamavam do currículo escolar que, comumente, não contemplava as suas necessidades e demandas específicas, e dos sujeitos escolares adultos que, em sua maioria, não consideravam a sua condição juvenil e nem lhes aferiam um lugar de sujeito no qual exercitassem pensamentos próprios e participação na gestão da vida escolar. Segundo salientaram Dayrell, Gomes e Leão (2010, p. 249),

\footnotetext{
os jovens denunciaram um tipo de relação humana e pedagógica baseada no desrespeito e no desprezo aos sujeitos da educação e demandaram outra postura por parte da escola e dos docentes. Isso indica que parece haver um choque cultural, geracional e um desrespeito ao aluno como sujeito social e cidadão de direitos no interior das escolas.
}

Desse modo, na condição de jovens, contariam apenas com a companhia dos seus pares. Nesse caso, Silva (2007, p. 205), ao analisar a formação de professores que estariam trabalhando ou trabalharão com adolescentes, afirmou que "quando estudantes universitários estão se graduando para trabalhar com adolescentes, esse segmento geracional e suas especificidades se tornam invisíveis".

Referente às suas famílias, no caso dos estudantes pobres, em sua maioria, ao chegarem no Ensino Médio, já teriam ultrapassado os pais no nível de escolaridade, contando de modo vago com o seu apoio para continuar os estudos, pois, de certo modo, já teriam atingido as expectativas paternas. E, ao concluírem esse nível de estudo, seriam convocados ao trabalho para colaborar na renda familiar. No caso dos alunos de classe média, na maioria estudantes de escolas particulares, conforme Lelis (2005), apesar de haver investimento familiar e obrigatoriedade de continuação dos estudos, muitos alunos não contavam com a parceria dos pais nas atividades escolares. Estes estariam mais preocupados com resultados do que com o processo de aprendizagem.

De outro modo, referindo-se a alunos pobres que ingressaram na universidade, Astigarraga (2010, p. 14) mostrou, acentuando tratar-se de prática diferenciada e minoritária, casos de pais pobres e semianalfabetos que apoiaram com afinco, do modo como puderam, a escolarização dos filhos. "Os jovens lembram-se dos seus pais como visionário, evoluído, doido. É forte, nas narrativas dos jovens, a força simbólica da figura paterna. Todos são unânimes em afirmar que seus pais fugiram da prática cotidiana de seu contexto". Mas, salientou essa autora, que, para a universidade, "o aluno é um número, uma matrícula, um dado estatístico frio” (p. 10), não havendo por

\begin{tabular}{|c|c|c|c|c|}
\hline Qovista Dialectus & Ano 4 & n. 11 & Agosto - Dezembro 2017 & p. $29-49$ \\
\hline
\end{tabular}


parte dela preocupação em saber quem de fato são seus alunos para, então, produzir políticas coerentes voltadas às necessidades dos estudantes pobres.

A abordagem assumida na maioria dos artigos pesquisados pareceu-nos assentarse na perspectiva escolar e juvenil apregoada pela escola moderna e republicana, cuja função seria efetivar a formação dos sujeitos jovens com base em valores humanistas e numa relação verticalizada de saber e poder. Outra perspectiva de estudos sobre a juventude estudantil, anunciada de modo tênue nos periódicos, dizia respeito à escola contemporânea numa dada perspectiva pós-moderna, situada na conformidade de uma sociedade pautada no espetáculo, no consumismo, no pragmatismo e no imediatismo. Nessa escola, os alunos seriam tratados como consumidores, alunos-clientes que desenvolveriam relação pragmática com a escola, compreendendo a escolarização como uma “negociação rentável” e imediatista. Segundo Oliveira e Tomazetti (2012, p. 196),

para a juventude contemporânea, assim, a informação assume caráter de conhecimento, o que vem a destituir o lugar das autoridades escolares na orientação de inúmeras questões vinculadas ao conhecimento do mundo e da sociedade tal como ela se apresenta em nossos dias. Diante disso, os saberes docentes são cada vez mais ignorados pelas novas gerações, ávidas de novas informações, como se a aprendizagem para a vida social pudesse prescindir de qualquer orientação das gerações mais velhas.

\section{Juventude, educação e mídias}

As mídias, de modo geral, e a televisão e o computador conectado à internet, em especial, vêm compondo parte importante do cenário no qual se desenvolve a vida de muitas pessoas. Mais recentemente, com o aparelho de telefonia móvel agregando funções de televisão e internet, os jovens têm exacerbado a ocupação do seu tempo com o uso das mídias. Tal situação vem demandando para a escola e seus profissionais a necessidade de incorporação das mídias nas práticas escolares e a preocupação com os seus usos feitos pelos jovens estudantes no seu cotidiano.

No conjunto dos artigos analisados neste trabalho, o tema juventude, educação e mídia apareceu de modo bastante relevante, sendo analisado por diversos pesquisadores. A importância das mídias na educação da juventude foi destacada por Bèvort e Belloni (2009, p. 1058-9), tendo assinalado que

as mídias são importantes e sofisticados dispositivos técnicos de comunicação que atuam em muitas esferas da vida social, [...] gerando novos modos de perceber a realidade, de aprender, de produzir e difundir conhecimentos e informações. São, portanto, extremamente importantes na vida das novas gerações, funcionando como instituições de socialização, uma

\begin{tabular}{|c|c|c|c|c|}
\hline Qovista Dialectus & Ano 4 & n. 11 & Agosto - Dezembro 2017 & p. $29-49$ \\
\hline
\end{tabular}


espécie de "escola paralela", mais interessante e atrativa que a instituição escolar, na qual crianças e adolescentes não apenas aprendem coisas novas, mas também, e talvez principalmente, desenvolvem novas habilidades cognitivas.

Diversos artigos apontaram a grande quantidade de tempo dedicado pelos jovens à televisão e ao computador, e conectando-se a sites de entretenimentos, relacionamentos e de busca de informação, travariam conversa com amigos, partilhando diversões, estudando, lendo e escrevendo, apreendendo conhecimentos e comportamentos e, em vários casos, incorporando-os à sua vida pessoal e escolar. De acordo com tais artigos, os jovens, vivenciando tal situação, formavam distintos grupos de sujeitos pertencentes a diferentes classes sociais, lugares e culturas, constituindo redes de comunicação que redimensionam as noções de tempo e espaço. Para Caimi e Oliveira (2012, p. 93-4), esses jovens seriam denominados geração homo zappiens, distinta das gerações anteriores, por constituir "uma nova espécie que atua em uma cultura cibernética global tendo como base os suportes multimídias [...], acessando múltiplos recursos tecnológicos".

Nesse caso, grande parte da população juvenil estaria concomitantemente conectada a diversos recursos midiáticos e desenvolvendo diversas atividades, tais como pesquisar, conversar, alimentar-se, estudar conteúdos escolares, ler e escrever. É assim que nas salas de aula tem sido comum dividirem seu tempo e atenção entre o professor, a exposição e a assimilação de conteúdos escolares e o manuseio do celular para conversar com amigos e pesquisar questões alheias à aula.

Vários artigos evidenciaram que muitos jovens ocupavam até mais de seis horas de seu dia assistindo à TV para se divertir e se informar. No rol dos estudos sobre a juventude e a televisão, Santana e Mercado (2011, p. 274-5), pesquisando estudantes de escola pública em Alagoas, afirmaram que os alunos têm na televisão a sua mais importante fonte de lazer e concluíram que os jovens

afirmam reconhecer os valores expostos na mídia televisiva e estabelecer a diferença com o seu cotidiano e com os seus próprios valores. Contudo, mesmo sem o perceber, acabam ressaltando qualidades que vêem, como a esperteza, o prestígio, o poder do dinheiro e da fama conseguidos sem muito esforço e sem os anos de escolaridade.

Trabalhando com grupos de jovens estudantes secundaristas e universitários, Fischer (2005a) assinalou que a televisão seria compreendida por esses estudantes como necessidade, presença, lazer e companhia; ficar em casa vendo TV funcionaria como prevenção aos riscos e perigos passíveis de serem encontrados nas ruas. Discutindo com

\begin{tabular}{|l|l|l|l|l|}
\hline Govista Dialectus & Ano 4 & n. 11 & Agosto - Dezembro 2017 & p. 29-49 \\
\hline
\end{tabular}


os jovens sobre como nos relacionamos com a TV, os modos de existência comunicados por essa mídia e como essa participaria da formação juvenil, a autora evidenciou que

\begin{abstract}
a escola é um lugar privilegiado para professores e alunos pensarem sobre esse tempo que estão vivendo; e que os debates a partir de produtos da mídia podem ser extremamente ricos, na medida em que as temáticas e as respectivas linguagens midiáticas, ao serem discutidas, expõem as contradições que todos vivemos, põem o dedo nas feridas que estamos sofrendo; por fim, abrem espaço para que se produza pensamento, que se criem idéias para além do que parece estar "enraizado em nós". (FISCHER, 2005b, p. 54)
\end{abstract}

O computador e o aparelho de celular conectados à internet parecem assumir posição majoritária no uso de mídias pela juventude. As reflexões sobre o uso da internet na vida escolar dos jovens foram referidas, de modo saliente, a três problematizações: as práticas de pesquisa escolar, as práticas de leitura e o tipo de sujeito estudante que estaria se constituindo a partir do universo virtual. Sobre as pesquisas que os jovens realizam na internet, Mostafa et al. (2004) elaboraram quatro categorizações: utilitária, informação da mídia, universitária e escolar, concluindo que a pesquisa escolar teria ficado em último lugar como atividade desenvolvida na internet.

Segundo Mamede-Neves e Duarte (2008), a internet estaria se afirmando como espaço privilegiado pelos jovens para a prática de leitura e escrita e como possibilidade de construção de conhecimentos, favorecendo a articulação de imagem e texto e a interação livre e autônoma com seus pares e outros leitores e escritores, como no caso dos fanfics, destacado por Oswald e Rocha (2013). Nesse sentido, apareceu com regularidade nos artigos a demanda para que fosse relativizada a ideia de que os jovens não liam e que a escola atualizasse as suas noções de leitura e de escrita, reconhecendo as transformações que estariam ocorrendo nos processos e técnicas de comunicação.

\title{
Juventude, educação e trabalho
}

Entre as diferentes problematizações sobre a relação entre juventude, educação e trabalho, foi destacado nos artigos analisados o sentido que deveria assumir o Ensino Médio, integrado ou não, e a inserção juvenil num mercado de trabalho em crise.

Quanto ao Ensino Médio, aliar formação geral e técnica seria a opção defendida pela maioria dos teóricos da área que se posiciona a favor da emancipação intelectual e política dos trabalhadores. Todavia, essa questão apresenta certa controvérsia entre esses teóricos, pois muitos empreendedores capitalistas estariam a defendê-la, a partir da lógica neoliberal, considerando necessária a capacitação intelectual do trabalhador

\begin{tabular}{|l|l|l|l|l|}
\hline Gevista 2 ialectus & Ano 4 & n. 11 & Agosto - Dezembro 2017 & p. 29-49 \\
\hline
\end{tabular}


para operar máquinas inteligentes e automatizadas, a fim de otimizar a produção de mercadorias requerida pela empresa flexível, a qual demanda trabalhadores flexíveis e detentores de saberes técnicos e teóricos, segundo assinalou Ferretti (2004).

$\mathrm{Na}$ discussão sobre esse tema, centrada nos termos da qualificação do trabalhador, cabe registrar que, em parte, a juventude não tem sido considerada na sua especificidade, pois a evidência sobre a formação do trabalhador termina por minimizar o aspecto etário e geracional e, sobressaindo a questão da luta de classes, a juventude como condição sociocultural parece ser subsumida na condição de classe trabalhadora.

Nos artigos consultados, o Ensino Médio Integrado, pensado sob a ótica dos estudantes, configuraria certa tensão, pois muitos alunos teriam optado por essa modalidade sem informações apropriadas sobre sua especificidade, as habilitações oferecidas e o maior tempo requerido para concluí-lo, retardando o ingresso no Ensino Superior. Assim, a escolha de uma carreira profissional no início da juventude seria uma dificuldade a provocar sofrimento psíquico em muitos estudantes, principalmente os de classe média, que anseiam mais por ingressar no Ensino Superior do que, de modo mais imediato, no mercado de trabalho, como afirmaram Rocha e Atem (2010).

Quanto à crise do emprego, ela estaria dificultando a inserção dos jovens no mercado de trabalho, sendo esses os sujeitos mais afetados pelo desemprego. Para minimizar os efeitos dessa crise, o Estado e o mercado de trabalho estariam a defender a necessidade de mais escolarização, visando ao alongamento do tempo de estudos e à postergação da entrada dos jovens no mercado de trabalho e na vida adulta.

Tal solução, todavia, não estaria colaborando para minimizar o problema, mas agregando outros problemas à condição juvenil. No caso dos jovens menos pobres, não estaria sendo incomum chegarem aos cursos de mestrado e doutorado ainda procurando emprego, como apontaram Mattos e Bianchetti (2011). Quanto aos mais pobres, segundo Faleiros (2008), o alongamento da vida estudantil estaria a lhes constituir dificuldades por precisarem trabalhar para poder estudar.

Também foi apontada dificuldade relacionada à mobilidade social ascendente pela via da escolarização, ao se considerar que muitos jovens com escolarização elevada estariam ingressando no mercado de trabalho em funções não condizentes com o nível de escolaridade conquistado, a exemplo de pós-graduandos que estariam ocupados em subempregos, sem vínculo empregatício e, portanto, sem direitos trabalhistas.

\begin{tabular}{|c|c|c|c|c|}
\hline Qevista Dialectus & Ano 4 & n. 11 & Agosto - Dezembro 2017 & p. $29-49$ \\
\hline
\end{tabular}


Outra questão referiu-se ao fato de que a reconfiguração do processo produtivo, derivada da revolução tecnológica, não estaria efetuando alterações significativas no processo de admissão da mão de obra. Assim, embora a escolarização básica seja anunciada como requisito fundamental, a admissão de novos trabalhadores, principalmente no setor industrial e para funções não qualificadas, ainda conta fortemente a indicação de familiares e de amigos, bem como a experiência profissional já adquirida e comprovada. A exigência de experiência profissional, segundo diversos artigos, estaria levando muitos jovens graduandos ao ingresso prematuro no mercado de trabalho para adquirir tal experiência, aliando estudo e trabalho. Tal experiência funcionaria como um capital a mais na disputa por empregos, conforme Silva (2004).

Segundo afirmou Corrochano (2004), a partir de pesquisa com jovens operários, estes não percebiam a influência da escolarização no trabalho que realizavam, alegando que as diferenças salariais, a ascensão funcional e a permanência na empresa não aconteciam em razão da escolaridade formal. Assim, parece que a escolarização alongada seria mesmo fundamental para o acesso ao mundo do trabalho por meio de concursos públicos e para o exercício de funções especializadas.

\section{Juventude e educação não-formal}

Entendemos por educação não-formal as modalidades educativas que acontecem fora da normatividade da instituição escolar, tais como programas promovidos pela esfera estatal, a exemplo do ProJovem e do Agente Jovem, e cursos pré-vestibulares populares, cursos profissionalizantes e experiências educativas e culturais fomentadas por agentes ou instituições da sociedade civil.

Sobre os cursos pré-vestibulares populares, os artigos não relataram expressividade no número de estudantes aprovados para cursar o ensino superior em universidades públicas, mas foi alegado que esses cursos favoreceram novos modos de sociabilidade, estímulo para a continuidade dos estudos e elaboração de projetos de futuro. Mitrulis e Penin (2006), a partir de estudo realizado sobre curso pré-universitário popular promovido pela USP, assinalaram que, diante da ausência de projetos de futuro ou formulação de projetos irreais baseados em "pensamentos mágicos" por parte de jovens estudantes pobres, os cursos pré-vestibulares possibilitaram-lhes a aquisição de saberes valorizados pelos exames vestibulares, além de certo empoderamento pessoal, importantes para a cidadania e o protagonismo.

\begin{tabular}{|l|l|l|l|l|}
\hline Qevista 2 Dialectus & Ano 4 & n. 11 & Agosto - Dezembro 2017 & p. 29-49 \\
\hline
\end{tabular}


Quanto a programas como o ProJovem e Agente Jovem, nos artigos analisados foram ressaltados o seu paralelismo descompassado com a escola oficial e a desvinculação com tal instituição, quando seria necessário um trabalho articulado, como demonstrou Sposito (2008). Nesses programas, foi evidenciada a positividade da concessão de pequena bolsa mensal para os alunos, os modos como a utilizavam e o que essa bolsa lhes propiciava, mas foi criticado o seu uso como pressão econômica para que os estudantes permanecessem na escola, sem que os promotores desses programas considerassem as críticas elaboradas pelos estudantes acerca da escola formal, como foi afirmado por Leão (2008), referindo-se ao programa Agente Jovem.

Também foi criticada a obrigatoriedade da participação dos estudantes em atividades comunitárias, na condição de trabalho voluntário, como contrapartida à concessão da bolsa. Para Sposito (2008), em referência ao ProJovem, a obrigatoriedade do trabalho voluntário seria uma forma de penalizar os jovens pobres, pois a jornada dupla de estudos, associada ao tempo dedicado às atividades comunitárias, funcionaria como interdição e controle do tempo dos jovens pobres nas suas vivências sociais.

Em outra perspectiva, as experiências de educação não-formal puderam servir como reconciliação dos jovens com a escola e como exercício de autonomia, criatividade, desenvolvimento de autoestima e aquisição de habilidades úteis à capacitação profissional, bem como o desenvolvimento de ações protagonistas com atividades no campo das artes. Isso de acordo com Laranjeira e Teixeira (2008), quando as experiências de educação não-formal assumiam postura crítica em relação à educação formal, favorecendo sedução e prazer aos jovens no trato com a sua aprendizagem.

\section{Juventude, educação e violência}

A violência tem acentuadamente atingido os jovens, principalmente os de sexo masculino, pobres e de cor negra ou parda. E a escola parece configurar-se como um campo ativo e passivo de práticas de violência em suas diversas modalidades. Nos estudos inventariados, encontramos análises sobre a violência física, tais como brigas, agressões, depredações etc., e a violência não física, como as agressões verbais, ameaças, discriminações e humilhações no interior da instituição escolar.

A posição da escola mediante a violência foi percebida como variante em diversas perspectivas. Por um lado, quando os envolvidos em atos de violência fisica eram estudantes pobres, a escola geralmente agia aos moldes policiais, carecendo de um

\begin{tabular}{|c|c|c|c|c|}
\hline Qevista Dialectus & Ano 4 & n. 11 & Agosto - Dezembro 201 & p. $29-49$ \\
\hline
\end{tabular}


plano educativo efetivo para combater a violência. Por outro lado, como salientou Arroyo (2007), muitas vezes a escola terminaria por exercitar outro tipo de violência: a exclusão do aluno violento, rejeitando-o, expulsando-o ou rejeitando sua matrícula.

As escolas particulares, geralmente, contam com aparato de segurança visando a prevenir e a coibir a violência física. No caso de violência não física entre alunos, a escola, pública ou privada, parece tender a agir com indiferença, talvez esperando que a situação se resolva por si. Contudo, a própria escola estaria se comportando desse mesmo modo quando esse tipo de violência é cometido por professores em relação aos alunos. Para os alunos, essa violência causaria sofrimento, humilhação e prejuízo à sua autoestima, como afirmaram Marriel et al. (2006), assinalando as reclamações estudantis quanto às agressões verbais, humilhações e ameaças cometidas por docentes.

Em situação oposta, quando a violência não física é praticada por estudante contra sujeitos escolares adultos, o encaminhamento adotado pela escola, na maioria das vezes, tem sido advertir o aluno, suspendê-lo ou expulsá-lo. Isso no caso de alunos de escola pública, pois segundo Salles e Silva (2008), quando se trata de alunos de classe média ou alta, em escolas particulares, a violência tenderia a ser tratada como "brincadeiras", “coisa de adolescentes". Todavia, foi destacado que a violência discente estaria causando danos à saúde dos docentes, afastamentos e o abandono da profissão.

Destacamos ainda a violência nas modalidades verbal e, muitas vezes, física praticada cotidianamente na escola contra os sujeitos considerados diferentes. Respaldada por políticas de normalização, essa violência tem sido materializada como discriminação, humilhação, desrespeito e segregação, chegando muitas vezes ao espancamento e à morte. As pessoas que mais sofrem essa violência seriam os gays, lésbicas, travestis, os gordos ou muito magros, os muito pobres, os nerds, os considerados pouco inteligentes, entre outros. Maggie (2006), a partir de estudo em escolas cariocas, constatou uma hierarquia de xingamentos, em ordem decrescente, referente à homossexualidade, à raça, à pobreza, ao peso e a ser bom ou mau aluno.

\section{Educação e jovens em conflito com a lei}

Os artigos que analisaram situações envolvendo adolescentes e jovens em conflito com a lei destacaram a exclusão social, familiar e escolar, a precarização dos processos e das condições de escolarização e a negação dos direitos desses sujeitos, salientando-se a predominância de sujeitos do sexo masculino, pobres e de cor negra.

\begin{tabular}{|l|l|l|l|l|}
\hline Q Rovista Dialectus & Ano 4 & n. 11 & Agosto - Dezembro 2017 & p. 29-49 \\
\hline
\end{tabular}


Segundo tais artigos, o cumprimento de medidas socioeducativas implicaria o processo de escolarização formal. No caso dos adolescentes não privados de liberdade, como assinalaram Gallo e Williams (2008), esses seriam rejeitados pelas escolas devido ao seu histórico de conflitos na escola, à incapacidade da escola para lidar com os desafios de seus comportamentos e ao estigma por estarem em conflito com a lei. Em referência aos professores, esses não contariam com capacitação adequada, além dos baixos salários que estariam a desestimular os docentes.

No caso dos educadores que atuam com adolescentes internos, foram salientadas as dificuldades encontradas para agirem dentro do novo paradigma educacional definido pelo Estatuto da Criança e do Adolescente, que estabeleceu o entendimento dos adolescentes como sujeitos de direitos e em processo de formação. Todavia, esses educadores estariam se deparando com a falta de condições para realizarem o seu trabalho em bases renovadas, podendo-se afirmar que o discurso difundido acerca das reformas institucionais operadas sob a premissa de novos paradigmas estaria sendo utilizado apenas como propaganda ideológica.

Assim, muitos educadores estariam executando o seu trabalho sem contar com formação especializada e mudanças nas práticas de gestores de casas de internação e órgãos públicos que, de fato, não estariam concebendo os adolescentes como sujeitos de direitos, reiterando as casas de internação como estabelecimento prisional. Segundo Cella e Camargo (2009), gestores e poderes públicos cobravam dos professores resultados pautados no imediatismo e na quantificação. Além disso, os professores demonstraram sofrer preconceito devido ao estigma social dos seus alunos, além da ausência de políticas eficazes para a integração entre escola, família e comunidade no processo educativo dos adolescentes. Desse modo, as medidas socioeducativas não estariam produzindo ressocialização e nem preparando os adolescentes em conflito com a lei para uma vida diferente após cumprirem tais medidas.

\section{Juventude, educação e sexualidade}

Há tempos a escola assumiu papel primaz nos processos de informação sobre sexo e de prevenção de riscos e desvios relacionados à sexualidade. Para Altmann (2007, p. 301), “a escola, sendo um lugar de transmissão de conhecimentos e dado o seu amplo alcance populacional, passa a ser responsabilizada por educar sexualmente os/as estudantes". Porém, segundo essa autora, o tratamento transversal sobre a sexualidade

\begin{tabular}{|c|c|c|c|c|}
\hline Qevista Dialectus & Ano 4 & n. 11 & Agosto - Dezembro 2017 & p. $29-49$ \\
\hline
\end{tabular}




\section{PROBLEMATIZACÕES CONSTITUINTES DA JUVENTUDE ESTUDANTIL... Dorgival Gonçalves Fernandes}

na escola, como aquele presente nos Parâmetros Curriculares Nacionais, tem sido de difícil implementação, sendo o tema da sexualidade, muitas vezes, abordado apenas nas disciplinas de Ciências ou Biologia, pautando-se no sentido da reprodução humana.

Nesse sentido, os jovens estudantes não estariam sendo formados para lidarem adequadamente com a sexualidade, reproduzindo mitos e preconceitos. Zucchi et al (2010) evidenciaram preconceitos e estigmas na escola contra alunos afetados pelo HIV e a ausência de atividades de prevenção de DST/Aids que incluíssem os que conviviam com HIV/Aids, além da falta de debates sobre estigma e discriminação nas escolas.

Segundo Assinelli-Luz e Fernandes Junior (2008), a educação sexual escolar não estaria produzindo os efeitos desejados, pois em sua pesquisa evidenciaram casos de rapazes que, dependendo das características físicas e econômicas da garota, não se preveniam contra a contracepção indesejada e a contaminação pelo HIV; no caso das moças, a vulnerabilidade relacionava-se a sentimentos de afeto e confiança no parceiro.

Quanto à questão de gênero e à homofobia, Teixeira-Filho, Rondini e Bessa (2011) alegaram que o sistema educacional dificultava a livre expressão de comportamentos não heteronormatizados, reforçando práticas homofóbicas e as desigualdades de gênero. Novena (2008) registrou, entre os jovens estudantes que analisou, preconceitos e estereótipos quanto à homossexualidade, sendo essa muitas vezes entendida como anormalidade provocada pela educação familiar. Para a autora, muitos estudantes, ancorados em valores propagados pela escola, estariam se orientando por uma perspectiva biologizante da sexualidade, restringindo-a a dimensão genital.

De acordo com Rosistolato (2009, p.377), a educação sexual precisaria aliar razão e afetividade, sendo preciso que a formação dos professores favorecesse a educação do corpo, do intelecto e das emoções para que pudessem educar os seus alunos de modo integral, e assim cuidar do amadurecimento dos alunos, para que "não enveredem por caminhos que os levem à gravidez indesejada, à aids e a doenças sexualmente transmissíveis e incentivar a produção de projeto individual que permita aos adolescentes guiar suas próprias vidas".

\section{Protagonismo juvenil e educação}

Na década de 1990, a participação ativa dos estudantes na sua aprendizagem emergiu como questão na perspectiva do protagonismo juvenil, tomado, segundo Ferretti, Zibas e Tartuce (2004, p. 414), como um conceito fluido e multifacetado, que

\begin{tabular}{|l|l|l|l|l|}
\hline Genista Qialectus & Ano 4 & n. 11 & Agosto - Dezembro 2017 & p. 29-49 \\
\hline
\end{tabular}


abarcaria diversas interpretações, tais como: "participação", "responsabilidade social", "identidade", "autonomia" e "cidadania". Para os autores, as Diretrizes Curriculares Nacionais do Ensino Médio tomaram o protagonismo juvenil como participação despolitizada e ativismo conformista, corroborando a ideia de que o protagonismo juvenil seria "um método de trabalho cooperativo fundamentado na pedagogia ativa".

Zibas, Ferretti e Tartuce (2006) asseveraram que o protagonismo juvenil praticado na escola estaria, em muitos casos, limitando-se a atividades extracurriculares geridas verticalmente. Assim, diversos artigos analisaram projetos educativos desenvolvidos em razão do protagonismo estudantil, nos quais a participação de estudantes estaria de dando de modo tutelado, dirigido e submetido a relações verticalizadas de poder, não favorecendo a autonomia e a criatividade estudantil.

Em sentido oposto, Victorio Filho e Berino (2007, p. 13) apontaram a escola como, também, espaço de produção de múltiplos modos de ser e estar, mesmo quando a ação de gestores e docentes colocava-se em contraposição ao universo juvenil. Para os autores, "falar em sonhos e desejos dos protagonistas da escola, os estudantes, é falar dos currículos que produzem e vivem. Formas ainda invisíveis à institucionalidade educacional e às operações maquínicas da rede de aparatos reguladores”.

Nesse caso, haveria ações de protagonismo estudantil que a escola, geralmente, não valorizava como ações educativas, e outras que a escola tentaria capturar para anular o protagonismo juvenil. No campo da comunicação, Dias (2005) destacou a interação juvenil na produção de textos e de modos de viver engendrados a partir da internet, apontando práticas de produção e uso de hipertextos pelos estudantes em sites e blogs. Nesses, os jovens estariam lendo, escrevendo, partilhando textos e imagens e produzindo conhecimentos de modo interativo, segundo uma estruturação híbrida, fragmentada e horizontalizada, contrapondo-se aos modos tradicionais de leitura e escrita na escola. Nessa perspectiva, Oswald e Rocha (2013) situaram os jovens fanfics que, em sites e blogs, constituem redes de leitura, discussão e reelaboração de obras literárias juvenis, minimizando a noção de autoria, ao tempo em que a exercitam.

Grupos de dança e de teatro foram afirmados como importantes espaços de protagonismo estudantil, como também outras expressões artísticas, como as praticadas por jovens cosplayeres. Segundo Rosa, Ferreira e Oswald (2010, p. 224), adereçados e fantasiados, em seus animencontros, esses jovens estariam forjando modos de ser temporários em sua expressividade estética, podendo "significar uma forma, consciente

\begin{tabular}{|c|c|c|c|c|}
\hline Q Rovita Dialectus & Ano 4 & n. 11 & Agosto - Dezembro 2017 & p. $29-49$ \\
\hline
\end{tabular}


ou não, para se firmar como sujeitos ativos socialmente". Nos grupos de teatro na escola, conforme Zibas, Ferretti e Tartuce (2006), seria comum os estudantes produzirem textos, figurinos, cenários e trabalhos de ator, afirmando-se como protagonistas, contando, porém, com um número limitado de jovens participantes.

Diversos artigos destacaram o movimento hip hop como prática de protagonismo juvenil pautada na contestação social. Assim, o hip hop ao adentrar na escola, salientaram Menezes, Costa e Ferreira (2010, p.88), “em sua interface com sua dimensão de movimento social, traz para o contexto escolar reflexões sobre a participação sociopolítica e a diversidade das práticas educativas", podendo produzir conflitos, antagonismo e mudanças na ordem escolar.

Os grêmios estudantis também foram destacados como espaços de produção de protagonismo juvenil. Porém, segundo Martins e Dayrell (2013), eles encontrariam dificuldades para se firmar como espaço de protagonismo juvenil devido ao descrédito de parte dos jovens com a política institucionalizada e à pressão exercida por parte de gestores escolares e partidos políticos que buscavam manipulá-los.

\section{Conclusão}

Neste trabalho buscamos produzir um estudo sobre a juventude estudantil brasileira na contemporaneidade a partir do discurso acadêmico posto em periódicos do campo da educação. Em tal empreitada, evidenciamos uma efetiva diversidade de temas e problematizações a partir de diversos encaminhamentos metodológicos e matrizes teóricas que engendram o campo de estudos acerca da juventude brasileira e as suas potencialidades analíticas no presente.

Entre os oito temas que elencamos e nos quais são alojadas diversas problematizações, podemos assinalar algumas questões que consideramos importante destacar no processo de constituição da juventude estudantil sobre o qual trabalhamos. A primeira delas refere-se às relações verticalizadas de poder na escola, produtoras de confusões e descompassos na vivência e na aprendizagem escolar dos jovens, o que faz com que a escola seja constituída como um campo de tensão e de conflitos para os jovens estudantes. Noutra perspectiva, destacamos a pouca visibilidade e o reduzido número de estudos sobre determinados grupos juvenis que constituem a juventude estudantil brasileira, como é o caso dos jovens rurais, indígenas, religiosos e os de descendência asiática; também é parca a alusão aos jovens ricos nesses estudos.

\begin{tabular}{|l|l|l|l|l|}
\hline Q ovista Qialectus & Ano 4 & n. 11 & Agosto - Dezembro 2017 & p. 29-49 \\
\hline
\end{tabular}


Em contrapartida, ressaltamos a positividade dos conflitos e experimentações produzidas por muitos estudantes que possibilitam configurações sobrepostas à disciplinarização e ao tutelamento estudantil, visando à constituição de si em outros moldes, principalmente no que diz respeito aos seus movimentos de produção no campo da cultura, a partir do uso da internet, no campo das artes, como é o caso de grupos de teatro e de dança constituídos no espaço escolar, e no campo da política, como evidenciaram diversos estudos acerca dos grêmios estudantis e do movimento hip hop.

Outra questão importante diz respeito à apreensão da juventude como categoria genérica e naturalizada presente em diversos estudos, apesar dos esforços de vários estudiosos do campo de estudos da juventude que há tempos trabalham para configurála conceitualmente para além da questão etária e a partir das suas características históricas, sociais, culturais e políticas.

Os temas e problematizações tratados neste trabalho ora se interpelam e se sobrepõem, ora se complementam e se colocam como interdependentes no processo discursivo que produz a juventude estudantil como objeto de estudo, de conhecimentos e de investimentos políticos. Entretanto, acreditamos ter conseguido elaborar um mapeamento produtivo para análises e compreensões acerca dos temas e problematizações que constituem, no tempo presente, a juventude estudantil brasileira.

\section{REFERÊNCIAS}

ALBUQUERQUE JUNIOR, Durval M. de. Por um ensino que deforme: o docente na pós-modernidade. In. Áurea da Paz Pinheiro e Sandra C. A. Peregrino (Org.). Tempo, memória e patrimônio cultural. Teresina: EdUFPI, 2010, p. 55-72.

ALTMANN, Helena. A sexualidade adolescente como foco de investimento políticosocial. Educação em Revista, Belo Horizonte, n. 46, p. 287-310, dez. 2007.

ARROYO, Miguel González. Quando a violência infanto-juvenil indaga a Pedagogia. Educação \&. Sociedade, Campinas, v. 28, n. 100, p. 787-807, out. 2007.

ASINELLI-LUZ, Araci; FERNANDES JÚNIOR, Nelson. Gênero, adolescências e prevenção ao HIV/AIDS. Pro-Posições, Campinas, v. 19, n. 2, maio/ago. 2008

ASTIGARRAGA, Andrea Abreu. Estratégias de acesso ao Ensino Superior entre jovens universitários com experiência de trabalho na infância. Educação Temática Digital, Campinas, v.12, n.esp., p.1-23, set. 2010.

BÉVORT, Evelyne; BELLONI, Maria Luiza. MÍDIA-EDUCAÇÃO: conceitos, história e perspectivas. Educação \&. Sociedade, Campinas, v. 30, n. 109, p. 1081-1102, set./dez. 2009.

\begin{tabular}{|c|c|c|c|c|}
\hline Q Rovita Dialectus & Ano 4 & n. 11 & Agosto - Dezembro 2017 & p. $29-49$ \\
\hline
\end{tabular}


CAIMI, Flávia Eloisa; OLIVEIRA, Sandra R. Ferreira de. Os jovens e a aula de história: entre tensões, expectativas e possibilidades. Revista Educação em Questão, Natal, v. 44, n. 30, p. 88-109, set./dez. 2012.

CELlA, Silvana M.; CAMARGO, Dulce M. P. de. Trabalho pedagógico com adolescentes em conflito com a Lei: feições da exclusão/inclusão. Educação \&. Sociedade, Campinas, v. 30, n. 106, p. 281-299, jan./abr. 2009.

CORROCHANO, Maria Carla. Jovens operários e operárias - experiência fabril e sentidos do trabalho. Perspectiva, Florianópolis, v. 22, n. 02, p. 425-450, jul./dez. 2004.

DAYRELL, Juarez; GOMES, Nilma L.; LEÃO, Geraldo. Escola e participação juvenil: é possível esse diálogo? Educar em Revista, Curitiba, n. 38, p. 237-252, set./dez. 2010.

DELEUZE, Gilles. Conversações. Tradução de Peter Pál Pelbart. Rio de Janeiro: 34, 1992.

DIAS, Ângela Correia. Processos comunicacionais da cultura jovem na rede social do ciberespaço. Educar, Curitiba, n. 26, p. 131-145, julho/dez. 2005.

FALEIROS, Vicente de Paula. Juventude: trabalho, escola e desigualdade. Educação \& Realidade, Porto Alegre, v.33, n. 02, p. 63-82, jul/dez. 2008.

FERRETTI, Celso João. Considerações sobre a apropriação das noções de qualificação profissional pelos estudos a respeito das relações entre trabalho e educação. Educação \& Sociedade, Campinas, v. 25, n. 87, p. 401-422, maio/ago. 2004.

FERRETTI, Celso João; ZIBAS, Dagmar M. L. e TARTUCE, Gisela Lobo B. P. Protagonismo juvenil na literatura especializada e na reforma do Ensino Médio. Cadernos de Pesquisa, v. 34, n. 122, p. 411-423, maio/ago. 2004

FISCHER, Rosa M. Bueno. Mídia e Educação: em cena, modos de existência. Educar. Curitiba, n. 26, p. 17-38, 2005a.

MÍDIA E JUVENTUDE: experiências do público e do privado na cultura. Cadernos Cedes, Campinas, v. 25, n. 65, p. 43-58, jan./abr. 2005 b.

FOUCAULT, Michel. Ditos e Escritos. Ética, sexualidade, política. MOTTA, Manoel Barros da. (Org.). Tradução de Elisa Monteiro e Inês A. D. Barbosa. Rio de Janeiro: Forense Universitária, 2004. v. 5.

GALlO, Alex Eduardo e WILLIAMS, Lúcia C. Albuquerque. A escola como fator de proteção à conduta infracional de adolescentes. Cadernos de Pesquisa, São Paulo, v. 38, n. 133, jan./abr. 2008.

LARANJEIRA, Denise Helena P. e TEIXEIRA, Ana M. Freitas. Vida de jovens: educação não-formal e inserção socioprofissional no subúrbio. Revista Brasileira de Educação, Rio de Janeiro, v. 13, n. 37 jan./abr. 2008.

\begin{tabular}{|l|l|l|l|l|}
\hline Govista Dialectus & Ano 4 & n. 11 & Agosto - Dezembro 2017 & p. 29-49 \\
\hline
\end{tabular}


LEÃO, Geraldo M. Pereira. Educar, ocupar, vigiar: alcances e limites de um programa para jovens pobres. Perspectiva, Florianópolis, v. 26, n. 1, 319-340, jan./jun. 2008.

LELIS, Isabel. O significado da experiência escolar para segmentos das camadas médias. Cadernos de Pesquisa, São Paulo, v. 35, n. 125, p. 137-160, maio/ago. 2005.

MAGGIE, Yvonne. Racismo e anti-racismo: preconceito, discriminação e os jovens estudantes nas escolas cariocas. Educação \&. Sociedade, Campinas, v. 27, n. 96, p. 739-751, out. 2006.

MAMEDE-NEVES, Maria A. Campos e DUARTE, Rosalia. O contexto dos novos recursos tecnológicos de informação e comunicação e a escola. Educação \&. Sociedade, Campinas, v. 29, n. 104, p. 769-789, out. 2008.

MARRIEL, Lucimar C. et al. Violência escolar e auto-estima de adolescentes. Cadernos de Pesquisa, v. 36, n. 127, jan./abr. 2006.

MARTINS, Francisco A. S.; DAYRELL, Juarez T. Juventude e Participação: o grêmio estudantil como espaço educativo. Educação \& Realidade, Porto Alegre, v. 38, n. 4, p. 1267-1282, out./dez. 2013.

MATTOS, Valéria de Bettio; BIANCHETTI, Lucídio. Educação continuada: solução para o desemprego? Educação \& Sociedade, Campinas, v. 32, n. 117, p. 1167-1184, out.-dez. 2011.

MENEZES, Jaileila de Araújo; COSTA, Mônica Rodrigues; FERREIRA, Danielle de F. Tavares. Escola e movimento hip hop: o campo das possibilidades educativas para a juventude. Educação Temática Digital, Campinas, v.12, n.esp., p.83-106, set. 2010.

MITRULIS, Eleny; PENIN, Sônia T. de Sousa. Pré-vestibulares alternativos: da igualdade à eqüidade. Cadernos de Pesquisa, v. 36, n. 128, maio/ago. 2006.

MOSTAFA, Solange Puntel. et al. LEITURA NAS TELAS: os jovens na internet. Educação Temática Digital, Campinas, v.5, n.2, p.58-74, jun. 2004.

NOVENA, Nadia Patrizia. Representações sociais de jovens sobre a sexualidade - um estudo com alunos de educação básica em Recife-PE. Revista Brasileira de Estudos Pedagógicos, Brasília, v. 89, n. 221, p. 162-181, jan./abr. 2008.

OLIVEIRA, Adriano Machado; TOMAZETTI, Elisete M. Quando a sociedade de consumidores vai à escola: um ensaio sobre a condição juvenil no Ensino Médio. Educar em Revista, Curitiba, n. 44, p. 181-200, abr./jun. 2012.

OSWALD, Maria Luiza; ROCHA, Sergio L. Alves da. Sobre juventude e leitura na "idade mídia": implicações para políticas e práticas curriculares. Educar em Revista, Curitiba, n. 47, p. 267-283, jan./mar. 2013.

PACKER, Abel L. Os periódicos brasileiros e a comunicação da pesquisa nacional. REVISTA USP, São Paulo, n.89, março/maio 2011.

\begin{tabular}{|l|l|l|l|l|}
\hline Govista Dialectus & Ano 4 & n. 11 & Agosto - Dezembro 2017 & p. 29-49 \\
\hline
\end{tabular}


REIS, Rosemeire. Experiência escolar de jovens/alunos do ensino médio: os sentidos atribuídos à escola e aos estudos. Educação e Pesquisa, São Paulo, v. 38, n. 03, p. 637652, jul./set. 2012.

ROCHA, Fúlvio Holanda; ATEM, Érica. Jovens e formação técnica no IF-CE: dilemas contemporâneos no processo de escolha profissional. Educação Temática Digital, Campinas, v.12, n.esp., p.64-82, set. 2010.

ROSA, Ana Carolina P. da Silva; FERREIRA, Helenice M. Cassino; OSWALD, Maria L. M. Bastos. PRÁTICAS CULTURAIS JUVENIS: máscaras contemporâneas. Revista da FAEEBA - Educação e Contemporaneidade, Salvador, v. 19, n. 33, jan./jun. 2010.

ROSISTOLATO, Rodrigo Pereira da Rocha. Orientação sexual na escola: expressão dos sentimentos e construção da autoestima. Revista Brasileira de Estudos Pedagógicos, Brasília, v. 90, n. 225, p. 367-384, maio/ago. 2009.

SALLES, Leila M. Ferreira; SILVA, Joyce M. A. de Paula e. Diferenças, preconceitos e violência no âmbito escolar: algumas reflexões. Cadernos de Educação, Pelotas, n.30, p. 149 - 166, jan./junho 2008.

SANTANA, Clésia M. Hora; MERCADO, Luis P. Leopoldo. A mídia televisiva e a transmissão de valores na ótica de alunos do Ensino Médio. Educar em Revista, Curitiba, n. 42, p. 263-277, out./dez. 2011.

SILVA, Mariléia Maria da. O trabalho para os jovens diplomados no novo modelo de acumulação capitalista. Perspectiva, Florianópolis, v. 22, n. 02, p. 405-424, jul./dez. 2004.

SILVA, Analise de Jesus da. A formação inicial e continuada de professores de adolescentes. Diálogo Educacional, Curitiba, v. 7, n. 21, p.199-212, maio./ago. 2007.

SPOSITO, Marília Pontes (Coord.). Juventude e Educação: interações entre a educação escolar e a educação não-formal. Educação \& Realidade, Porto Alegre, v. 33, n. 2, p. 83-98, jul/dez. 2008.

SPOSITO, Marilia Pontes; GALVÃO, Izabel. A experiência e as percepções de jovens na vida escolar na encruzilhada das aprendizagens: o conhecimento, a indisciplina, a violência. Perspectiva, Florianópolis, v. 22, n. 02, p. 345-380, jul./dez. 2004.

TEIXEIRA-FILHO, Fernando Silva; RONDINI, Carina Alexandra; BESSA, Juliana Cristina. Reflexões sobre homofobia e educação em escolas do interior paulista. Educação e Pesquisa, São Paulo, v. 37, n. 4, p. 725-742, dez. 2011.

VICTORIO FILHO, Aldo; BERINO, Aristóteles de Paula. Culturas juvenis, cotidianos e currículos. Currículo sem Fronteiras, v.7, n.2, p.7-20, Jul/Dez 2007.

ZIBAS, Dagmar M. L.; FERRETTI, Celso J.; TARTUCE, Gisela Lobo B. P. Micropolítica escolar e estratégias para o desenvolvimento do protagonismo juvenil. Cadernos de Pesquisa, São Paulo, v. 36, n. 127, jan./abr. 2006

\begin{tabular}{|l|l|l|l|l|}
\hline Govista Dialectus & Ano 4 & n. 11 & Agosto - Dezembro 2017 & p. 29-49 \\
\hline
\end{tabular}


ZUCCHI, Eliana Miura. et al. Estigma e discriminação vividos na escola por crianças e jovens órfãos por Aids. Educação e Pesquisa, São Paulo, v.36, n.3, p. 719-734, set./dez. 2010.

\begin{tabular}{|l|l|l|l|l|}
\hline Q & Anialata 4 & n. 11 & Agosto - Dezembro 2017 & p. 29-49 \\
\hline
\end{tabular}

